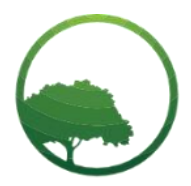

Research in Business \& Social Science

IJRBS VOL 10 NO 6 ISSN: 2147-4478

\title{
Application of social network analysis for determining the suitable social media influencers
}

\author{
(iD) Mochamad Yudha Febrianta ${ }^{(a)}$ (iD) Yusditira ${ }^{(b)}$ (iD) Sri Widianesty ${ }^{(c)}$ \\ ${ }^{(a, b, c)}$ School of Economics and Business, Telkom University, Indonesia
}

\author{
ARTICLE INFO \\ Article history: \\ Received 19 August 2021 \\ Received in rev. form 15 Sep. 2021 \\ Accepted 16 Sept 2021 \\ Keywords: \\ Social Network Analysis, Social \\ Media Marketing, Degree of \\ Centrality, Closeness Centrality, \\ Betweenness Centrality, Eigenvector \\ Centrality \\ JEL Classification: \\ O15, P36
}

\begin{abstract}
A B S T R A C T
Virtual Hotel Operator (VHO) trend is growing rapidly, especially in Indonesia. Two of the most popular VHO in Indonesia are OYO and RedDoorz, both have been competing to attain the first position. Both OYO and RedDoorz have their own social media marketing strategies. For example, OYO persuades other conventional hotels to collaborate and use the OYO platform in their businesses. On the other hand, RedDoorz was recorded as the most visited Virtual Hotel Operator Platform in 2019, based on the data of Konsumen Jakpat 2019. OYO and RedDoorz also utilize social media to promote their services such as Instagram and Twitter. For advertising their businesses in social media, $O Y O$ and RedDoorz often use some social media influencers or known as influencer social media marketing. Influencers should be able to effectively deliver the messages and influence people's decisions to use the products or services they advertise. This study aims to further explore the social media marketing strategy employed by $\mathrm{OYO}$ and RedDoorz. The results of Social Network Analysis by using "oyoindonesia" and 'reddoorz' as keywords in social media Twitter showed that RedDoorz has a bigger social network and more users involved in spreading their information than OYO. On the other hand, OYO's official account on Twitter is more efficient in performing its function as marketing media.
\end{abstract}

(C) 2021 by the authors. Licensee SSBFNET, Istanbul, Turkey. This article is an open access article distributed under the terms and conditions of the Creative Commons Attribution (CC BY) license (http://creativecommons.org/licenses/by/4.0/).

\section{Introduction}

The Indonesian Central Bureau of Statistics recorded a significant growth of online hotel bookings in 2018, which reached around US \$1.986million. This amount has increased by almost US\$200million since 2017 and is predicted to keep increasing until US\$2.879million in 2023. One of the main factors in this significant growth is the rising trends of Virtual Hotel Operators (VHO). VHO is an online platform providing relatively affordable accommodation in collaboration with various hotels (Capodieci, 2019)(Kim, 2019). VHO becomes popular among travelers because it can provide much cheaper accommodation hotels with standard facilities. The hotels that collaborated with VHO will pay some amounts of commissions or employ a profit-sharing agreement. In 2018, the Indonesian Central Bureau of Statistics stated that there were 24.916 units of accommodation hotels while the star hotels were only 3.314 units. This number of accommodation hotels shows the vast number of demands for these facilities. On the other hand, the growth of VHO causes a substantial drop in star hotel occupancies as stated by the Indonesian Central Bureau of Statistics.

Two of the most popular VHOs in Indonesia are OYO and RedDoorz. OYO Hotels and Homes is a technology-based hospitality company that originated in India. It offers leased and franchised hotels, homes, and apartments with affordable price ranges. OYO reached $1900 \%$ of growth in just six years of its existence with 720 hotels and more than 20.000 rooms. RedDoorz is another VHO collaborating with accommodation hotels and homes to promote their properties. RedDoorz is recorded as the most used VHO platform by consumers (Permana and Hidayat, 2020). One of RedDoorz's key successes is it's brand awareness strategy. RedDoorz's most popular tagline is \#BisaAja which was used in their marketing campaign in October 2019. This tagline gathered around 16,3 million viewers on their Youtube and Instagram accounts and drove RedDoorz to reach the highest top-of-mind awareness in

* Corresponding author. ORCID ID: 0000-0002-1326-2195

(C) 2021 by the authors. Hosting by SSBFNET. Peer review under responsibility of Center for Strategic Studies in Business and Finance.

https://doi.org/10.20525/ijrbs.v10i6.1347 
November 2019. OYO and RedDoorz use social media as their main marketing tools, one of those social media is Twitter. Social media allows companies to reach a wider market and make direct contact with their customers. Social media posts from VHO's accounts are repeatedly shared by other individuals or community' accounts so that the messages are widely known.

Other than the VHO's own content, the user-generated content (UGC) also influences the market's perception of VHOs (Narangajavana Kaosiri, 2019). UGC is the user's online positive or negative opinions that are accessed publicly and could support customer's behavior coding (Narangajavana Kaosiri, 2019)(Agarwal, 2020). Massive information dissemination can blur its validity and increase the possibility of hoaxes. Hoaxes can be harmful whether for the companies or the users; therefore, it is important to check the validity of the information. Information validity can be verified by obtaining the dissemination patterns and the origin of the information. Besides that, knowing the information dissemination patterns and key players can help companies to design a more effective media social marketing strategy.

One of the methods used to see relationship patterns and the key player in a network is Social Network Analysis (SNA). SNA is a method used for analyzing a social relationship by measuring the density and actors in a network (Dado, 2017)(Camacho, 2020). This study uses SNA to determine the relationship patterns and key players in information dissemination related to OYO and RedDoorz. The social media used as the case study is Twitter. Although studies regarding SNA have been done by many researchers, in the field of VHO especially in Indonesia, it is still scarcely done. This study can be a reference for other studies that aim to analyze the digital information network patterns for other companies or fields in Indonesia. The rest of this paper is organized as follows: Section 2 explains previous research relevant to VHO and SNA, section 3 describes the methodology used in this study, section 4 analyzes the study's results, and section 5 consists of conclusion and recommendation for future works.

\section{Literature Review}

Social media marketing is a product or service marketing method focusing on the use of social media to help achieve marketing goals and broaden brand awareness (Lou, 2019)(Farooq, 2018). Social media can be an effective tool for companies to share content related to their products or services, build brand awareness, and influence customer's wants. On the other hand, the massive flow of digital information circulating in social media could hinder a company's marketing strategy due to the dissemination of invalid information or known as hoaxes. Social Network Analysis (SNA) is one of the methods used for determining social relationship patterns and key players in the spreading of information in social media (Camacho et al,, 2020)(Wang et al., 2020). SNA focuses on the relationship among actors in a network and measures network density which consists of the degree of centrality, closeness centrality, eigenvector centrality, and betweenness centrality. The information dissemination patterns can be determined by portraying actors as nodes and the relationship as the lines (edges).

Many social studies have been done by using SNA. In socio-political areas, Tawadros and Soliman (2019) combined dynamic network analysis, text mining, and natural language processing (NLP) to identify the key actors in the Syrian crisis. Their proposed method was validated in identifying key actors in complex international crises. Another study from Tawadros (2019) proposed a combination of network analysis and other data manipulation techniques to investigate the pattern of terror among terrorist organizations. Their study results were helpful in generating a terror landscape for terrorist organizations.

Moreover, in a business-related area, Litterio et al. (2017) used SNA as a tool to detect potential influencers for online marketing. The study proposed a classification matrix to detect significant individuals integrated into a Facebook sporting fans page. The matrix was proven to be effective in finding potential actors to efficiently spread a message within the community. Dias et al. (2020) analyzed the relation between demographic factors and the researcher's importance in the co-authorship network in published papers in Brazilian journals. While Nourian et al. (2018) proposed an SNA-based model of crowd-sensed data to predict the flow of human mobility trails.

Most of the research in SNA was conducted in foreign countries, there are only a few studies done in Indonesia. Hidayat and Rizaldi (2019) calculated the centrality in social networks by using the SNA among male long-tail monkeys (Macaca fascicularis). Pratama and Iqbal (2018) mapped the tourism stakeholder network in Kota Batu by applying the SNA method. Alifa Noor (2019) also used the SNA to study the information flow among batik entrepreneurs in Pekalongan. Related to social media, Mahdi and Dodie (2017) utilized SNA to analyze the spread of Indonesia's country branding "Wonderful Indonesia". While Anwar et al. (2018) analyzed the spread of pornographic content among Indonesian users in social media by using the SNA. None of those studies were done on the rising phenomenon of VHOs, so this study was carried out to fill the gap.

\section{Research and Methodology}

The framework of this study is based on the user-generated content (UGC) scattered across Twitter correlated to OYO and redDoorz. UGC is the social media content created by non-expert users that can be accessed by the public (Moens, 2014). The UGC was gathered by using a data crawling method. Twitter is chosen as the case study because it can be accessed publicly which makes data gathering easier. The data were then used for categorizing the influential actors in spreading information about OYO and RedDoorz. The Social Network Analysis extracts a large volume of information related to OYO and RedDoorz and measures its centrality to determine the most influential actor. Figure 1 summarizes the proposed framework of this study. 


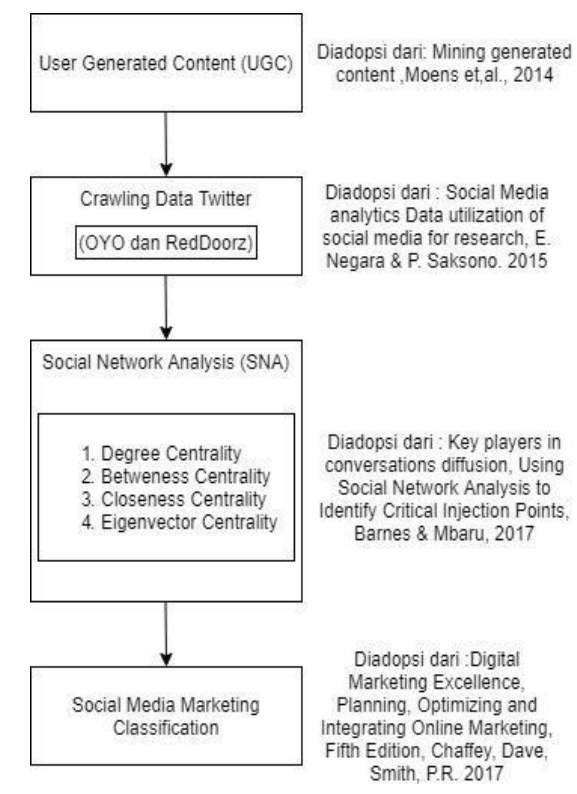

Figure 1: Research Framework

The samples for this study are Twitter posts with "oyoindonesia" and 'reddoorz" as the keywords and posted from January 17, 2021, until February 15, 2021, gathered by using RStudio V 3.6 software. Then, the Gephi software was used as a tool to visualize the patterns of information dissemination networks. The Gephi showed the information clusters and the most influential key players or influencers.

\section{Result and Discussion}

\section{Normality}

The data gathered with the keyword "reddoorz" during the time frame were 25.020 tweets. But, not all of them can be used as input for this study. After selecting and filtering the data, only 1.007 tweets were sufficient to be processed. While for the keyword "oyoindonesia", there were 4.759 tweets but after the data cleaning process, only 222 tweets can be used. Those tweets were used as input for Gephi 0.9.2. This study used the Fruchterman Reingold and Yifan Hu layout because it is easier to read and interpret.

\section{RedDoorz}

Figure 2 shows the visualization of the social interaction network for the keyword "reddoorz". There are a few clusters of user interactions discussing RedDoorz in their tweets. The social network visualization uses the undirected graph for the node relationship. Different clusters indicate different topics of discussion in each cluster.

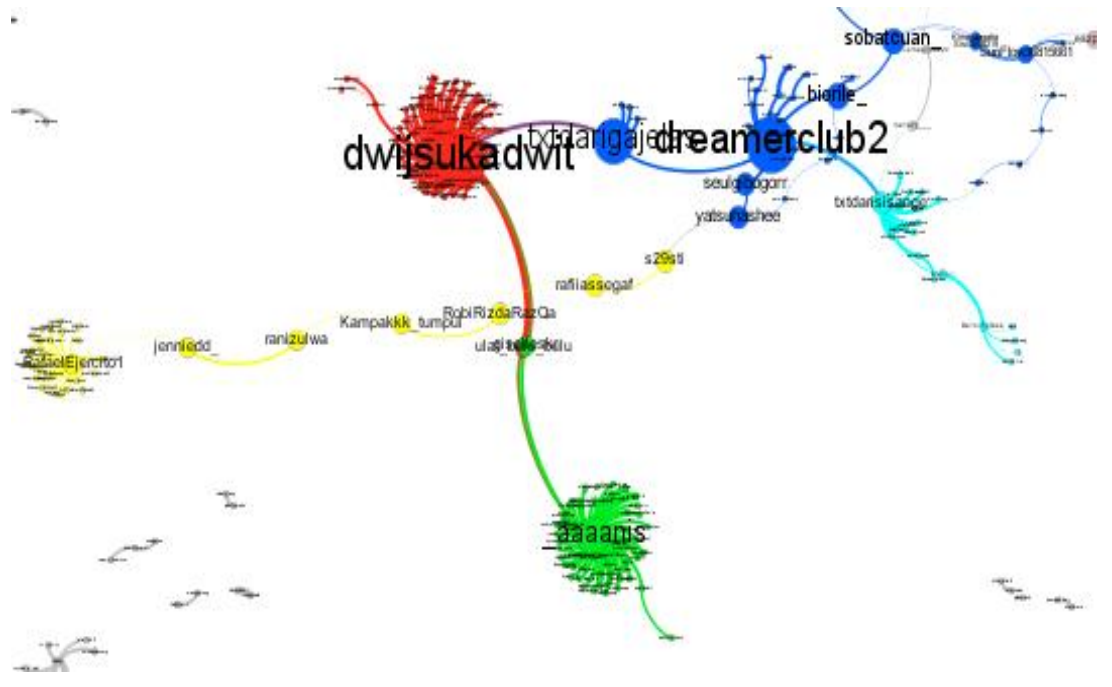

Figure 2: Visualization of RedDoorz Network

The social network properties for RedDoorz are summarized in Table 1. 
Table 1: Social Network Properties for RedDoorz

\begin{tabular}{ll}
\hline Network Properties & Quantity \\
\hline Node & 1.007 \\
\hline Edge & 741 \\
\hline Average Degree & 1,472 \\
\hline Diameter & 26 \\
\hline Average Path Length & 7,837 \\
\hline
\end{tabular}

The node represents users involve in discussing RedDoorz, so 1.007 nodes mean there were 1.007 users that were discussing RedDoorz.The edge represents discussion related to RedDoorz, 741 edges mean that there were 741 separated discussions in Twitter about RedDoorz in the timeframe of the data gathering period. The next property, the average degree explains the average of the user's relationship. The higher its average degree means that the user has more relationships so they can spread the information wider. 1,472 average degree means the relationship among users in the network is 1,472 relationships. The diameter is the maximum distance between nodes in the network. A bigger diameter causes a longer time for the information to spread. 26 diameter means the information needed to take 26 steps to spread out. The last property, the average path length is the average distances between nodes in the network. 7,837 of average path length means that the information was quite long to disseminate.

There are three main clusters for RedDoorz and each cluster has its own key player based on their centrality value. The dwijsukadwit account holds an important role in conveying information related to RedDoorz such as promotion codes, discount programs, etc. For the green cluster, _aaaanis is selected as the key player who also shares information about promotion codes and discount programs but in different tweet-style. As for the yellow cluster, RafaelEjercito1 is the key player who also shares the RedDoorz's marketing programs. Table 2 shows the centrality properties of each key player.

Table 2: Centrality Properties for Key Players

\begin{tabular}{llll}
\hline Centrality & dwijsukadwit & aaaanis & RafaelEjercito1 \\
\hline Degree Centrality & 75 & 63 & 27 \\
\hline Betweenness Centrality & 25715,5 & 14786,5 & 6669 \\
\hline Eigenvector Centrality & 1,0 & 0,673308 & 0,11589 \\
\hline Closeness Centrality & 0,206107 & 0,169173 & 0,084138 \\
\hline
\end{tabular}

The degree of centrality portrays the account's number of relationships with other accounts. The higher the degree of centrality means the more relationships the account has and the easier it is to spread the information. Betweenness centrality describes the account's role as a mediator between other accounts, while the eigenvector centrality shows its relation with other important accounts in the network. The last centrality property which is closeness centrality represents the account's easiness in conveying information to other accounts.

\section{OYO Hotels and Homes}

During the data gathering period, there were 4.759 tweets obtained related to the keyword "oyoindonesia". After preprocessing the data, there were only 222 tweets that can be used as the input data. Figure 3 is the visualization of OYO social network.

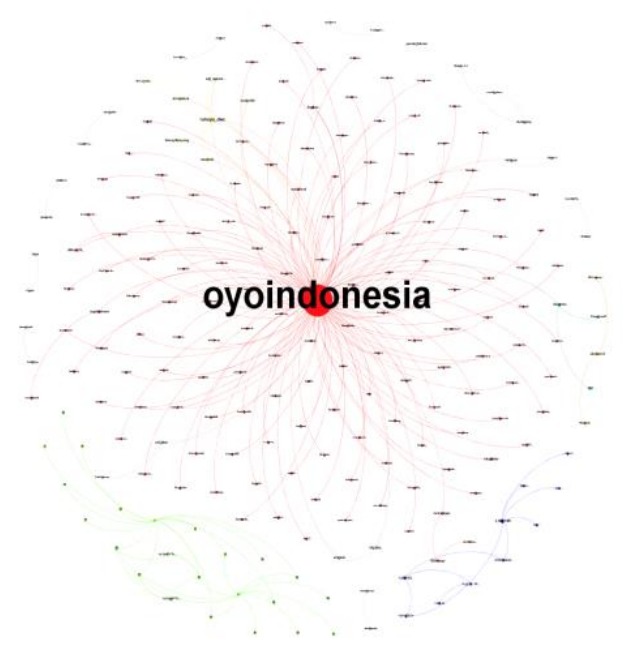

Figure 3: Visualization of OYO Social Network 
Based on figure 3, there was only one cluster in the OYO social network and the properties of this network are summarized in Table 3 .

Table 3: OYO Social Network Properties

\begin{tabular}{ll}
\hline Network Property & Quantity \\
\hline Node & 222 \\
\hline Edge & 229 \\
\hline Average Degree & 2,063 \\
\hline Diameter & 5 \\
\hline Average Path Length & 2,109 \\
\hline
\end{tabular}

Based on its properties, there were 222 users and 229 conversations discussing "oyoindonesia" during the data gathering time frame. The average relationship for users in the network is 2,063 . The diameter was 5 and the average path length was 2,109 . It means that the information in OYO social network can spread faster, but the network is smaller than RedDoor's.

OYO social network only has one key player, oyoindoensia account, which is the official account of OYO Hotels and Homes in Indonesia. The centrality properties for this account are shown in Table 4.

Table 4: Centrality Properties for OYO Social Network

\begin{tabular}{ll}
\hline Centrality & Oyoindonesia \\
\hline Degree Centrality & 75 \\
\hline Betweenness Centrality & 25715,5 \\
\hline Eigenvector Centrality & 1,0 \\
\hline Closeness Centrality & 0,206107 \\
\hline
\end{tabular}

\section{Discussion}

Based on the results from the social network analysis, the RedDoorz official account in Indonesia is not selected as the key player. It means that the RedDoorz official account is quite effective in playing its role as marketing media. The dwijsukadwit account posted the most tweets related to RedDoorz such as promotion code, discount programs, customer reviews, etc. Account dwijsukadwit also posted other interesting tweets that could hold people's interest in its accounts. Based on its effectiveness in spreading information, account dwijsukadwit is capable of influencing people's opinion regarding RedDoorz on Twitter. The RedDoorz can design a marketing campaign involving the dwijsukadwit account, whether by using dwijsukadwit as their ambassador or influencer or collaborating with their Twitter official account.

While for OYO Hotels and homes, their official account has been performing its role effectively because the analysis results showed oyoindonesia account as the key player in its social network. The official oyoindonesia account as the key player gives other benefits for the company with its high engagement rate. The customers can directly interact with the company and the information coming from an official account is easier to validate too which can give assurance to its customers.

\section{Conclusions}

Based on the analysis results and discussion, it can be concluded that SNA is a useful method for determining the key player in the company's information dissemination network. This knowledge can be one of the basis for companies in designing their social media marketing strategies. RedDoorz, which is awarded as the top-of-mind awareness, has a bigger social network with more users involved. But, their official Twitter account is not selected as one of the key players. It means that RedDoorz needs to evaluate their official social media account's effectiveness and they also can start involving the selected key players as part of their social media marketing campaign. While OYO has a smaller social media network, their official account has been performing well in their function as marketing media with many followers and high customer's engagement rate. But, OYO still needs to widen their social media network so their information can reach wider audiences. This study is limited to the VHO's social network in Twitter. Future research can use other social media platforms and other business areas as the subjects.

\section{References}

Agarwal, M., (2020). Importance of User Generated Content as a part of Social Media Marketing that drives Customere $\mathrm{s}$ Brand Awareness and Purchase Intentions. The International Journal of Analytical and Experimental Modal Analysis, 12(2), p.3071.

Alifa Noor, A., (2019). Analisis Eko-Efisiensi Pada Usaha Kecil dan Menengah (UKM) Batik Larissa Kota Pekalongan (Studi Pada Batik Tulis Larissa) (Doctoral dissertation, Faculty of Social and Political Sciences).

Anwar, M.T., (2018). Analisis Pola Persebaran Pornografi pada Media Sosial dengan Social Network Analysis. Jurnal Buana Informatika, 9(1), 43-52. 
Camacho, D., Panizo-Lledot, Á., Bello-Orgaz, G., Gonzalez-Pardo, A. and Cambria, E., (2020). The four dimensions of social network analysis: An overview of research methods, applications, and software tools. Information Fusion, 63, 88-120.

Capodieci, A., Elia, G., Grippa, F. and Mainetti, L., (2019). A network-based dashboard for cultural heritage promotion in digital environments. International Journal of Entrepreneurship and Small Business, 36(4), 453-475.

Dado, M. and Bodemer, D., (2017). A review of methodological applications of social network analysis in computer-supported collaborative learning. Educational Research Review, 22, 159-180.

Dias, A., Ruthes, S., Lima, L., Campra, E., Silva, M., Bragança de Sousa, M. and Porto, G., (2020). Network centrality analysis in management and accounting sciences. RAUSP Management Journal, 55, 207-226.

Farooq, A., Joyia, G.J., Uzair, M. and Akram, U., (2018), March. Detection of influential nodes using social networks analysis based on network metrics. In 2018 International Conference on Computing, Mathematics and Engineering Technologies (iCoMET) (1-6). IEEE.

Froehlich, D.E. and Brouwer, J., (2021). Social network analysis as mixed analysis. The Routledge Reviewer's Guide to Mixed Methods Analysis, 209.

Hidayat, A., Rizaldi, R. and Nurdin, J., (2019). Jaringan Sosial (Social Network) Antar Jantan Monyet Ekor Panjang (Macaca fascicularis) Di Gunung Meru, Padang, Sumatera Barat. Jurnal Biologi UNAND, 7(1), 14-20.

Kim, S. and Lee, W.S., (2019). Network text analysis of medical tourism in newspapers using text mining: The South Korea case. Tourism Management Perspectives, 31, 332-339.

Litterio, A.M., Nantes, E.A., Larrosa, J.M. and Gómez, L.J., (2017). Marketing and social networks: a criterion for detecting opinion leaders. European Journal of Management and Business Economics.

Lou, C. and Yuan, S., (2019). Influencer marketing: how message value and credibility affect consumer trust of branded content on social media. Journal of Interactive Advertising, 19(1), 58-73.

Moens, M.F., Li, J. and Chua, T.S. eds., (2014. Mining user generated content. CRC press.

Narangajavana Kaosiri, Y., Callarisa Fiol, L.J., Moliner Tena, M.A., Rodriguez Artola, R.M. and Sanchez Garcia, J., (2019). Usergenerated content sources in social media: A new approach to explore tourist satisfaction. Journal of Travel Research, 58(2), 253-265.

Nourian, P., Rezvani, S., Valeckaite, K. and Sariyildiz, S., (2018). Modelling walking and cycling accessibility and mobility: The effect of network configuration and occupancy on spatial dynamics of active mobility. Smart and Sustainable Built Environment.

Permana, I.S., Hidayat, T. and Mahardiko, R., (2020). An analysis to set the regulation up for tourism industry in new normal pandemic of Covid-19. In Proc International Conference on Cultural Heritage, Education, Sustainable Tourism, and Innovative Technologies (CESIT)(2020) In Press.

Pratama, R. and Iqbal, M., (2018). Analisis Pemetaan Jejaring Stakeholder Pariwisata Di Kota Batu Dengan Menggunakan Metode Social Network Analysis (SNA). Jurnal Administrasi Bisnis, 54(1), 179-188.

Tawadros, A.S. and Soliman, S., (2019). Identifying key actors in an international crisis using dynamic network analysis: Syrian crisis case study. Journal of Humanities and Applied Social Sciences.

Wang, Y., Thangasamy, V.K., Hou, Z., Tiong, R.L. and Zhang, L., (2020). Collaborative relationship discovery in BIM project delivery: A social network analysis approach. Automation in Construction, 114, 103147.

Publisher's Note: SSBFNET stays neutral with regard to jurisdictional claims in published maps and institutional affiliations.

\section{(a) (1)}

(C) 2021 by the authors. Licensee SSBFNET, Istanbul, Turkey. This article is an open access article distributed under the terms and conditions of the Creative Commons Attribution (CC BY) license (http://creativecommons.org/licenses/by/4.0/).

International Journal of Research in Business and Social Science (2147-4478) by SSBFNET is licensed under a Creative Commons Attribution 4.0 International License. 